\title{
El camino hacia la formulación de una nueva política migratoria en Brasil. De la visión militar restrictiva a la apertura
}

\author{
Tomás MiLton Muñoz Bravo*
}

Artículo recibido: 25 de julio de 2017

Artículo aprobado: 12 de diciembre de 2018

Doi: https://doi.org/10.12804/revistas.urosario.edu.co/desafios/a.5963

Para citar este artículo: Muñoz Bravo, T. M. (2020). El camino hacia la formulación de una nueva política migratoria en Brasil. De la visión militar restrictiva a la apertura. Desafíos, 32(1), 1-37. https://doi.org/10.12804/revistas.urosario.edu.co/desafios/a.5963

\section{Resumen}

Durante la última dictadura militar brasilera (1964-1985) se impulsó una política migratoria enfocada a 'proteger' los empleos de los trabajadores locales, restringir la presencia de extranjeros ligados a movimientos de izquierda y salvaguardar sus propios intereses políticos. Con el regreso de los gobiernos civiles y el cambio de patrones migratorios, inició un proceso paulatino para superar esa lógica restrictiva a finales del siglo XX e inicios del XXI, en un contexto en el que la integración regional, a través del Mercado Común del Sur (Mercosur), coadyuvó a promover la libre circulación de personas en dicha organización internacional suramericana. El presente trabajo explica, por medio del análisis cualitativo de una serie de factores seleccionados, la transición vivida en Brasil que pasó de una política migratoria restrictiva, basada en la ley de extranjería de 1980, a la formulación de una política abierta en respuesta

\footnotetext{
* Profesor en el Centro de Relaciones Internacionales de la Facultad de Ciencias Políticas y Sociales, Universidad Nacional Autónoma de México (México). Correo electrónico: tomasmilton@hotmail.com. ORCID: https://orcid.org/0000-0002-3365-0902
} 


\title{
2 I Tomás Milton Muñoz Bravo
}

a cambios en los patrones migratorios, a elementos politicos y económicos internos y externos, y a compromisos internacionales contraidos por el pais.

Palabras clave: Brasil, migración, politica migratoria, Mercosur.

\section{The Road to Get a New Migratory Policy for Brazil. From the Restrictive Military Vision to an Open Policy}

\begin{abstract}
During the last Brazilian military dictatorship (1964-1985), the migration policy focused on 'protecting' the jobs of local workers. It also promoted the restriction of the presence of foreigners linked to leftist movements and to safeguard the government's political interests. With the return of civilian governments and the change of migration patterns, a gradual process began to overcome the restrictive logic at the end of the $20^{\text {th }}$ and the beginning of the $21^{\text {st }}$ century, in a context in which regional integration, through Mercosur, helped to promote the free movement of people within this South American international organization. The present work explains, through a qualitative analysis of a series of selected factors, the transition experienced in Brazil from a restrictive migration policy, based on the immigration law of 1980, to the formulation of an open procedure that responded to changes in the migratory patterns, the internal and external political and economic elements and international commitments assumed by the country.
\end{abstract}

Keywords: Brazil, migration, migration policy, Mercosur. 


\title{
O caminho à formulação de uma nova política migratória no Brasil. Da visão militar restritiva à abertura
}

\begin{abstract}
Resumo
Durante a última ditadura militar brasileira (1964-1985) promoveu-se uma politica migratória focada em 'proteger' os empregos dos trabalhadores locais, restringir a presença de estrangeiros ligados a movimentos de esquerda e salvaguardar seus próprios interesses politicos. Com o regresso dos governos civis e a mudança de patrões migratórios, iniciou um processo paulatino para superar essa lógica restritiva no final do século XX e começos do XXI, em um contexto no que a integração regional, através do Mercado Comum do Sul (Mercosul), contribuiu a promover a livre circulação de pessoas em dita organização internacional sul-americana. O presente trabalho explica, através da análise qualitativa de uma série de fatores selecionados, a transição vivida no Brasil que passou de uma política migratória restritiva, baseada em lei de estrangeria de 1980, à formulação de uma política aberta em resposta a mudanças nos patrões migratórios, a elementos políticos e económicos internos e externos e a compromissos internacionais contraídos pelo país.
\end{abstract} Palavras-chave: Brasil, migração, política migratória, Mercosul.

\section{Introducción}

Transformaciones sociales, económicas y políticas registradas en Suramérica en las últimas cuatro décadas produjeron un aceleramiento en la movilidad de las personas entre países limítrofes. Dicha dinámica ha conducido a "nuevas formas y estructuras de las sociedades, repercutiendo directamente en los procesos de desarrollo de los países y de la región en su conjunto" (OIM \& IPPDH del Mercosur, 2016, p. 7), lo que a su vez ha obligado a los Estados a generar respuestas para atender los retos que conlleva la migración internacional.

La implementación del modelo neoliberal a partir de la década de 1980 y las recurrentes crisis económicas y políticas no solo dieron pie a la emigración de suramericanos hacia países desarrollados, también se incrementó la movilidad intrarregional, producto sobre todo de dinámicas "de atracción y expulsión de fuerza de trabajo caracterizada 
por una mayor proporción de personas en edad productiva y una acelerada incorporación de las mujeres a estas dinámicas" (García \& Gainza, 2014, p. 76).

En la actualidad se puede apreciar que los países de la región principalmente receptores de inmigración limítrofe son Argentina, Brasil y Chile, mientras que los mayoritariamente expulsores son Bolivia, Paraguay y Uruguay (Mondol, 2010, p. 18). A lo anterior hay que sumarle el arribo de migrantes y solicitantes de asilo de otras partes del mundo a la zona, especialmente provenientes de China, Haití y de países africanos.

Brasil, de forma particular, tiene como principales patrones migratorios la inmigración temporal y permanente de extranjeros, sobre todo de naciones limítrofes; la llegada de solicitantes de asilo y refugio (en particular de haitianos, africanos y ahora venezolanos); y la existencia de colectividades brasileras en el extranjero con las que se pretende mantener un vínculo estrecho, situaciones no contempladas en la ley de migración de 1980, promotora de una política restrictiva. Al respecto, se entiende por políticas migratorias a los actos y medidas (leyes, decretos, resoluciones, directrices y actos administrativos) que lleva a cabo un Estado encaminados a regular la entrada, salida y permanencia de la población nacional o extranjera en su territorio (Corte Interamericana de Derechos Humanos, 2003, p. 192).

La elaboración y aplicación de dichas políticas son potestad de cada Estado, y en Brasil han sido modificadas en diferentes pasajes de la historia y han oscilado de la atracción de inmigrantes europeos - tras su independencia en el siglo XIX_ - hasta la restricción a la presencia de extranjeros en la última dictadura militar o la vinculación con sus emigrados en el mundo.

Las políticas migratorias varían frente a cierto tipo de circunstancias y de migrantes. Por ejemplo, se puede dar prioridad a la seguridad territorial, al fomento económico o, incluso, a las percepciones ${ }^{1}$ que se

\footnotetext{
1 En la hechura de estas políticas convergen varios elementos de relevancia y uno de ellos es la percepción que se tiene de los migrantes, la cual puede oscilar entre una imagen
} 
tengan de los extranjeros, según los intereses de cada Estado o del grupo en el poder al frente del gobierno, y "suelen concebirse dentro del marco de fronteras abiertas o cerradas, el libre tránsito de inmigrantes y la imposición de limitaciones estrictas en cuanto a número y características de los migrantes” (Massey, Durand \& Malone, 2009, p. 161).

En el caso brasilero, la dictadura militar que ejerció el poder entre las décadas de 1960 y 1980 limitó el acceso al territorio ante el temor del ingreso de extranjeros que 'pusieran' en riesgo el empleo y salario de los locales, aunque en realidad la política migratoria restrictiva se circunscribió a la Doctrina de Seguridad Nacional en el Cono Sur, concebida en el marco de la Guerra Fría y aplicada por países latinoamericanos bajo la influencia de Estados Unidos para garantizar la estabilidad y seguridad interna frente a las amenazas de revoluciones llevadas a cabo por movimientos de izquierda (Leal, 2003, pp. 74-76).

Con dicha doctrina, las dictaduras militares de la región, incluida la brasilera, asumieron la creencia de que el mayor peligro para Suramérica era "el de las guerras limitadas de tipo subversivo y la agresión comunista indirecta producida a través de la capitalización del descontento de tipo local" (Tapia, 1980, p. 112), por lo que buscaron la menor influencia posible del exterior, por medio del control de las fronteras para neutralizar al 'enemigo'.

Tras el retorno de los gobiernos civiles a partir de 1985, el inmigrante dejó de ser considerado una competencia desleal para los trabajadores locales o un potencial elemento subversivo (Dos Santos \& Assunção, 2016) y de forma paulatina se fueron implementando acciones gubernamentales para atender las diferentes aristas de los procesos migratorios que afrontaba Brasil; sin embargo, en el Estado brasilero aún seguía vigente la restrictiva ley migratoria de 1980, recuerdo latente de la última dictadura.

positiva o xenofílica —en la que se ve al extranjero como un factor de cambio y de desarrollo- y una negativa o xenofóbica — en la que el inmigrante es señalado de provocar daño a la sociedad de acogida- (Mármora, 2002, pp. 70-77). 


\section{6 / Tomás Milton Muñoz Bravo}

Durante las administraciones de Fernando Henrique Cardoso (19952002), de Luiz Inácio Lula da Silva (2003-2011) y de Dilma Rousseff (2011-2016) se emprendieron acciones y programas que respondieran a los patrones migratorios afrontados por Brasil, así como a los compromisos internacionales contraídos en materia de derechos humanos y al proceso de integración en el Mercosur, que contempla desde 2009 la posibilidad de la libre movilidad para los ciudadanos de los países firmantes del Acuerdo sobre Residencia; ${ }^{2}$ empero, es hasta el gobierno del centro-derechista Michel Temer que se logra la aprobación de una nueva ley de migración, parte angular en la actual política migratoria del país amazónico.

Se esperaba que una nueva ley pudiera ser sancionada durante el gobierno de Dilma, especialmente ante la necesidad de facilitar el ingreso de inmigración calificada en un contexto de sostenido crecimiento económico ${ }^{3} \mathrm{y}$ de cara a la realización de dos eventos deportivos de envergadura como el Mundial de Fútbol de 2014 y los Juegos Olímpicos de 2016, pero las crisis política y económica afrontadas por ese país, y que llevó a la destitución de Dilma, retrasó la aprobación de la normativa en el Congreso.

Por lo anterior, en el presente trabajo se analizan cuáles fueron los factores y elementos que llevaron al Estado brasilero a transitar de una política migratoria restrictiva y fundamentada en la ley militar de 1980 a una política migratoria que facilita la inmigración, procura fortalecer la relación con los brasileros en el extranjero, responde al proceso de integración en el Mercosur y tiene como colofón una nueva normativa.

A pesar de la complicada coyuntura que vive Brasil, recordar que estuvo en recesión entre 2014 y $2016^{4}$ —debido en gran parte al

\footnotetext{
2 El acuerdo fue firmado en 2002, pero entró en vigencia plena en 2009 con la participación inicial de Brasil, Argentina, Uruguay, Paraguay, Bolivia y Chile.

El crecimiento económico registrado entre 2003 y 2014 le permitió a Brasil sacar de la pobreza a 29 millones de personas, reducir la inequidad en la distribución de ingresos y acrecentar la clase media (Banco Mundial, 2016).

4 Brasil pasó de registrar en 2010 un crecimiento en su producto interno bruto (PIB) del $7,5 \%$ a crecer apenas un $0,1 \%$ en 2014 . Un año después se tuvo una caída del $3,8 \%$ y en
} 
desplome en los precios de las materias primas en los mercados internacionales-, y que afrontó una crisis social y política tras la destitución de Dilma en 2016, el arribo cuestionado de Temer al Palacio del Altiplano y la encarcelación de Lula en 2018, se parte de la hipótesis de que la formulación paulatina de una política migratoria progresista en Brasil, alejada de la visión restrictiva de la última dictadura militar y respaldada por una nueva ley en la materia, responde a una serie de elementos sociales (cambios en los patrones migratorios), políticos (gobiernos que dejaron atrás la visión de seguridad) y económicos (crecimiento sostenido entre 2002 y 2014), así como a compromisos internacionales (tratados suscritos en materia de derechos humanos) y de integración regional (en particular el Mercosur).

Para comprobar la hipótesis, en un primer apartado del trabajo se hace una revisión de la importancia de la migración en la historia de Brasil. En la segunda parte se analizan los actuales patrones migratorios internacionales que afronta el país, así como elementos económicos y políticos que han influido para conformar una nueva política migratoria, alejada de la lógica de seguridad y concatenada con el área de libre residencia impulsada por el Estado brasilero en el Mercosur. En la parte final del artículo se exploran otras respuestas estatales a los patrones migratorios y algunos de los retos observados para poner en marcha la nueva ley de migración en un ambiente político, económico y social aún adverso.

En metodología se recurre a un análisis cualitativo de los factores socioeconómicos y políticos internos y externos que han definido a Brasil en las últimas décadas y a sus procesos migratorios internacionales (inmigración, emigración, retorno y refugio). También se realiza una revisión de estadísticas poblacionales y económicas para explicar la formulación y aplicación de políticas migratorias en diferentes momentos de la historia de Brasil, pero con énfasis en los hechos acontecidos en las últimas tres décadas, que han permitido transitar de una política pública restrictiva a una de apertura. 


\section{8 / Tomás Milton Muñoz Bravo}

El trabajo se sustenta en la revisión y análisis de informes, bases de datos y estadísticas, programas, decretos internos y acuerdos internacionales, así como de literatura especializada. Cabe señalar que se da especial énfasis en los factores de atracción y de expulsión (Micolta, 2005, pp. 68-69) $)^{5}$ presentes en Brasil para entender de mejor manera la conformación de sus patrones migratorios y, por ende, la adecuación de políticas públicas para afrontar los diferentes retos en materia migratoria durante las últimas décadas.

\section{Evolución histórica de los procesos migratorios de Brasil}

Brasil ha transitado por cuatro grandes procesos migratorios que han moldeado su historia y su composición poblacional. En las primeras tres fases, el Estado suramericano se caracterizó sobre todo por ser un importante receptor de migrantes extrarregionales, sin embargo, a partir de la década de 1980 se observa una importante presencia de brasileros en otras partes del mundo, así como una complejización de los patrones migratorios. Al iniciar el presente siglo el país es tanto receptor como expulsor de migrantes, elementos que a continuación se desarrollan.

\section{Las primeras tres fases de migración internacional en Brasil}

La historia de la migración internacional en Brasil inicia antes de su conformación como Estado independiente con la llegada a inicios del siglo XVI de los colonialistas portugueses, quienes, luego de expulsar a otros conquistadores franceses y holandeses de las costas y de algunos territorios ubicados en el noreste brasilero, impulsaron la llegada

\footnotetext{
5 La teoría de los factores push and pull parte de que existen una serie de factores que empujan a los migrantes a salir de sus países de origen y al mismo tiempo buscan otros lugares de asentamiento que ofrezcan mejores condiciones de desarrollo, es decir, lugares de destino que resultan atractivos para inmigrantes. Los factores de expulsión van desde presión demográfica, falta de acceso a la tierra, bajos salarios o niveles de vida pauperizados, hasta falta de libertades políticas y represión. Los factores de atracción que se asocian a los lugares de destino son los contrarios.
} 
de migrantes provenientes de Portugal y de esclavos africanos para trabajar en los cultivos de azúcar.

Al igual que la corona española, el reino portugués promovió entre los siglos XVI y XVIII la llegada de colonos al 'Nuevo Mundo' por medio de incentivos como el otorgamiento de tierras y de semillas, el pago de pasajes, el suministro de herramientas para el cultivo y exenciones fiscales, con el propósito de poblar territorio en regiones norteñas y australes, y así evitar que cayera en manos de otras potencias colonizadoras de la época (Muñoz, 2015, p. 13).

Empero, el grueso de la inmigración en la época colonial que arribó a la llamada 'América portuguesa' procedía de África. Se estima que entre 1500 y 1850 (año en que se prohibió la entrada de esclavos a Brasil por medio de la Ley Eusébio de Queirós) se introdujeron unos cuatro millones de esclavos negros en territorio brasilero (Patarra, 2011, p. 160) para trabajar en las plantaciones ante la carencia de mano de obra indígena.

A diferencia de la 'América española', en la que la población indígena era mayoría en comparación a la población blanca o mestiza a pesar de las muertes por enfermedades y maltratos que padeció, en el caso de la 'América portuguesa' la inmigración forzada de millones de esclavos fue determinante para darle a Brasil su actual composición étnica.

Esta primera gran etapa de migraciones internacionales concluye debido a los procesos de independencia en América Latina y a la paulatina disminución en la llegada de esclavos africanos. Debido a lo anterior, al arrancar la segunda década del siglo XIX, del total de la población de Brasil, casi el 50\% era de origen africano, los blancos poco menos del $25 \%$, los mestizos y mulatos casi el 18\% y los indígenas el $9 \%$ (Morse, 1964, p. 147).

Con el nacimiento de Brasil como Estado independiente en 1822 se inició una segunda etapa de migraciones internacionales, que terminó a inicios del siglo xx y se caracterizó por una serie de políticas encaminadas a atraer nuevos flujos de inmigrantes europeos para poblar 
territorios y cubrir mano de obra en la agricultura, especialmente en los campos de café en entidades como San Pablo. En este período el gobierno brasilero también decidió a partir de 1850 implementar medidas legales que pondrían fin al tráfico de esclavos (Toledo, 2011, p. 67).

La política de promoción de la llegada de europeos, por medio de medidas que incluían el pago de pasajes, se concibió también bajo la lógica de que era necesario 'europeizar' al naciente país con los elementos culturales más deseados (Póvoa \& Sprandel, 2010, p. 56), y es por ello que la gran mayoría de los inmigrantes provino de Portugal, Italia, España y Alemania, aunque también se incentivó a inicios del siglo xx la llegada de japoneses para el cultivo y cosecha del café debido en gran parte a que cayeron las llegadas de flujos europeos. ${ }^{6}$

Se estima que entre 1870 y 1930 llegaron unos 4,4 millones de personas, originarios principalmente de los cuatro países europeos antes mencionados y de Japón (OIM, 2010, p. 9); aunque vale la pena destacar que en algunos Estados brasileros la diversidad de orígenes de los inmigrantes fue más amplia, por ejemplo, en Paraná, ubicado en la región sur del país, el principal origen de la inmigración entre 1829 y 1911 fue el polaco, con el 49,2\%; seguido por el ucraniano, con el 14,1\%; el alemán, con el 13,3\%; el italiano, con el 8,9\%; y el ruso, con el 4,2\% (González, 2003, p. 69).

En el período de entre guerras y en un contexto marcado por la Gran Depresión de 1929, la inmigración internacional decae de forma drástica en Brasil producto del desempleo y de la lógica de seguridad y de desconfianza que empieza a imperar en el mundo ante la inminencia de una nueva conflagración mundial. En la década de 1930, el Estado brasilero decidió endurecer su legislación para evitar o limitar el ingreso de extranjeros, de esta forma se emitió el Decreto 19482, en 1930, con el que se suspendió cualquier tipo de inmigración por

\footnotetext{
6 La disminución de los flujos europeos tuvo que ver con varios factores, uno de ellos fue la prohibición del gobierno italiano en 1902 a sus connacionales de que salieran rumbo a terceros países en los que sus condiciones de vida serían deplorables, y Brasil era considerado un país que no ofrecía condiciones propicias (Muñoz, 2015, p. 16).
} 
espacio de un año; también se modificó la ley de cuotas establecida en la Constitución para limitar desde 1937 la inmigración de cualquier país a solo el $2 \%$ del total de la población (OCDE, 2010, p. 238). ${ }^{7}$

En la tercera etapa de la migración internacional, desarrollada básicamente entre las décadas de 1930 y 1960, se observa un cambio en los patrones migratorios, pues Brasil pasó de ser un gran receptor de inmigrantes europeos a ser un Estado destinatario de migraciones intrafronterizas y expulsor de migrantes a países limítrofes, como Paraguay. Además, predominaron los movimientos internos de la población hacia las grandes metrópolis como reacción al modelo de sustitución de importaciones implementado en América Latina y con el que se buscaba dejar de depender de los artículos provenientes de las grandes potencias y generar la industrialización de las economías subdesarrolladas (Pellegrino, 2003, p. 12).

El modelo de sustitución de importaciones en Brasil produjo un considerable crecimiento económico desde finales de la década de 1940 hasta inicios de la década de $1960,{ }^{8}$ lo que permitió un relajamiento en la normatividad migratoria y dio pie a una última gran oleada de inmigrantes europeos en la década de 1950.

En 1945 se publicó el Decreto 7967 para facilitar el ingreso a inmigrantes, aunque se dio prioridad a los flujos europeos, y durante los períodos presidenciales de Getulio Vargas (1930-1945) se impulsó una política de asimilación para que los extranjeros formaran parte de una sola identidad brasilera (González, 2003, p. 190); sin embargo, los arribos masivos de inmigrantes europeos ya no se recuperaron y la inmigración de ultramar tendió a ser cada vez más esporádica,

\footnotetext{
Otros elementos que influyeron en la decisión del Estado brasilero para restringir la inmigración en el período referido fueron la preocupación ante la posible llegada de representantes de movimientos anarquistas con presencia en Europa y algunos lineamientos generados en las conferencias internacionales americanas en la década de 1920 sobre nacionalidad, extradición y asilo político.

8 Brasil vivió una época dorada con la implementación del modelo de industrialización por sustitución de importaciones. Entre 1940 y 1980 el país alcanzó tasas de crecimiento anuales del 7\% (Marquetti, et al., 2014).
} 
dirigida a zonas urbanas para cumplir con trabajos en los que se carecía de personal local capacitado.

Otro elemento por destacar en esta tercera etapa de migración internacional en Brasil es el arribo en 1964 de la última dictadura militar, que gobernó al Estado hasta 1985. Durante esas dos décadas, la imagen del extranjero se vinculó con la seguridad y se impusieron normatividades y actitudes de rechazo hacia los migrantes económicos y hacia los exiliados y refugiados políticos, provenientes de otros países suramericanos en los que las dictaduras militares habían emprendido una serie de persecuciones y asesinatos en contra de opositores. Incluso en la década de 1970, solo se permitía el acceso a nuevos migrantes como residentes permanentes si tenían contrato con empresas brasileras, pues las autoridades locales buscaban proteger la fuerza laboral local (Gomes, 2003, p. 87).

La última dictadura militar, a la que se le debe la ley sobre extranjería de 1980, provocó la salida de miles de brasileros y dificultó el ingreso de migrantes y de refugiados. Sobre estos últimos, pocos pudieron resguardarse en Brasil y lo consiguieron gracias a la intervención de organizaciones caritativas y religiosas, en colaboración con la Oficina del Alto Comisionado de las Naciones Unidas para los Refugiados (ACNUR), y pese a las restricciones de las autoridades brasileras, que operaban en coordinación con dictaduras de gobiernos vecinos en la persecución de opositores (Póvoa \& Sprandel, 2010, p. 57).

A pesar de las trabas migratorias impuestas y en un panorama en el que sobresalían los problemas económicos y sociales internos, Brasil transitó en las últimas dos décadas del siglo Xx hacia una cuarta fase de migración internacional, en la que se destacaron el arribo de migrantes económicos provenientes mayoritariamente de países fronterizos (Bolivia, Perú, Argentina y Uruguay) y de China; y el éxodo de brasileros al exterior. 


\section{La cuarta fase de migraciones internacionales en Brasil.}

\section{Cambio de paradigma}

La imposición de políticas restrictivas, pero, al mismo tiempo, la necesidad de mano de obra coadyuvaron al asentamiento de miles de inmigrantes limítrofes de forma indocumentada, lo que obligó a las autoridades a implementar dos programas de amnistía, el primero de ellos en 1988 y el segundo en 1998, que regularizaron a más de 81000 personas, la mayoría de origen boliviano (23000), chino (19000), argentino (4500), uruguayo (4400) y peruano (4180) (Gomes, 2003, pp. 88-89). Esta situación se vio reflejada en el censo de 2000, pues, si bien es cierto que las colectividades europeas, junto a la japonesa, aún eran las más copiosas entre la población extranjera, los grupos de migrantes provenientes de países fronterizos se consolidaron como fuentes de inmigración.

Al iniciar el siglo XXI, la población total de Brasil era de 174,5 millones de personas, de las cuales 683830 eran extranjeras. Casi una tercera parte de los inmigrantes había nacido en Portugal (213203), 70000 en Japón, unos 55000 en Italia, 43604 en España y 19000 en Alemania (Celade, 2000). En cuanto a los inmigrantes de países suramericanos, los paraguayos eran los más representativos con casi 29000 personas viviendo en Brasil, seguidos por los argentinos (27573), los uruguayos (24740), los bolivianos (20388) y los chilenos con 17131 (Celade, 2000).

Aunque la inmigración documentada e indocumentada seguía formando parte de la realidad brasilera, las crisis económicas de 1980 y 1990, el agotamiento del modelo de sustitución de importaciones y la adopción del modelo neoliberal influyeron para que Brasil transitara de ser un país eminentemente receptor de inmigrantes a uno también expulsor. En 2002, el Departamento de Asistencia Consular del Ministerio de Relaciones Exteriores calculaba en 1965000 el número de brasileros en el extranjero, para 2007 se estimaba que la colectividad brasilera en el extranjero superaba los 3 millones de personas y los principales destinos eran Estados Unidos, Japón, Paraguay y algunos países de la Unión Europea (Patarra, 2011, p. 169). 
Esta diversificación, de destinos en el extranjero, en cuanto a los factores de atracción, obedece a circunstancias particulares, por ejemplo, en el caso de la emigración de brasileros hacia Estados Unidos se dio en su mayoría en condición indocumentada y con el propósito de acceder a trabajos mejor remunerados. Los migrantes brasileros en la Unión Americana se empleaban en servicios personales, salud, hoteles, restaurantes, construcción y comercio, además presentaban niveles educativos altos, pues un $81 \%$ contaba con estudios secundarios terminados y un $39 \%$ con estudios universitarios o técnicos equivalentes (OCDE, 2010, p. 240).

A su vez, los brasileros que emigraron a trabajar en Japón, principalmente en la industria manufacturera, lo hicieron en forma documentada gracias a una serie de medidas implementadas por el gobierno del país asiático que incentivó la llegada de brasileros descendientes de japoneses ante el incremento de la tasa de envejecimiento y la disminución de su tasa de natalidad.

En lo que respecta a los brasileros en Paraguay, la migración tiene sus antecedentes en 1960 y se institucionalizó en 1975 por medio de las gestiones de los dos gobiernos que permitieron el asentamiento de brasileros en las áreas rurales paraguayas de los departamentos de Alto Paraná, Canindeyú y Amambay, fronterizos con Brasil. Tras la entrada en vigor del Tratado de Alianza y Cooperación Económica de 1975 , se puso en marcha una estrategia para poblar territorio paraguayo con más de 1200000 brasileros (equivalente al 45\% de la población de Paraguay de la época) en un área de casi 122000 kilómetros cuadrados (cerca del 30\% del territorio paraguayo).

El objetivo primordial del tratado era crear un 'cerco vivo' alrededor del lago de Itaipú y asegurar la expansión de la frontera económica brasilera en Paraguay, lo que se consideraba benéfico para los dos países por la llegada masiva de migrantes extranjeros para desarrollar la agricultura comercial en zonas poco habitadas; sin embargo, generó la expulsión de campesinos paraguayos que residían en la región y un estatus de indefinición legal para buena parte de los llamados 'brasiguayos', que no son reconocidos ni por Brasil, ni por Paraguay (Texidó, et al., 2003, p. 56). 
La creciente emigración de brasileros en las dos últimas décadas del siglo xx y en los primeros años del XXI a países desarrollados o fronterizos y la recepción de flujos provenientes de países limítrofes, producto de interacciones comerciales y sociales históricas, y de la existencia de dinámicas de complementariedad de mercados de trabajo en la región, definen la cuarta fase de la migración internacional en Brasil.

\section{De la visión militar restrictiva a la construcción de una política migratoria abierta}

A lo largo de su historia independiente, el Estado brasilero ha impulsado una serie de políticas migratorias dirigidas, según las condiciones de la época y de los gobiernos en turno, a atraer población extranjera, regularizar la presencia de indocumentados, limitar o impedir la llegada de inmigrantes y, de forma más reciente, propiciar la libre movilidad y de residencia en la zona Mercosur, en conjunto con sus socios del bloque regional.

Para entender la transición en las últimas tres décadas de la lógica de seguridad impuesta por la dictadura militar hacia la apertura en las políticas dirigidas a los procesos migratorios, es necesario revisar los patrones migratorios afrontados por Brasil en lo que va del siglo XxI (producto de factores socioeconómicos que generan dinámicas de atracción, expulsión y retorno), así como los elementos políticos internos y los compromisos regionales e internacionales - sobre todo en materia de derechos humanos y de integración — suscritos tras el regreso de la democracia.

\section{Los retos que suponen para Brasil} los actuales patrones migratorios

El Brasil contemporáneo afronta como principales patrones migratorios: a) la recepción de inmigrantes, especialmente de Estados suramericanos, pero también de personas provenientes de otras regiones, como África; b) la consolidación de colectividades brasileras en el exterior; y c) el retorno de connacionales provenientes sobre todo de 
España, Italia y Japón, en donde las oportunidades laborales empezaron a escasear a raíz de la crisis financiera y económica de 2008 (Fernandes, et al., 2015; Cavalcanti, 2015).

\section{Brasil como polo de atracción de migraciones}

Respecto a este patrón, es necesario reiterar que desde finales del siglo xx Brasil se consolidaba como un polo de atracción de migrantes limítrofes, situación que continuó en la primera década del siglo XXI, producto de la bonanza económica y de las perspectivas favorables de crecimiento. En 2010, el país registró un crecimiento económico de su PIB del 7,5\% y las materias primas (mineral de hierro, soya, petróleo crudo y azúcar crudo), principales productos de exportación brasileros, tenían precios altos, y China adquiría cada vez más bienes procedentes de Suramérica. Además, la crisis financiera mundial de 2008 no había afectado de forma considerable a la principal economía de América Latina y, de acuerdo con un informe del Banco Mundial, para 2012 la clase media brasilera se había incrementado hasta superar poco más del 50\% de la población total (Ferreira, et al., 2013, p. 150).

El crecimiento sostenido en casi una década abonó para que la candidata apoyada por Luiz Inácio Lula da Silva, la también integrante del Partido de los Trabajadores (PT), Dilma Rousseff, ganara las elecciones presidenciales de 2010 y empezara a gobernar un año después en un escenario de mayor participación de Brasil en política exterior y con dos retos próximos por afrontar, la organización y desarrollo del Mundial de Fútbol de 2014 y los Juegos Olímpicos de 2016, considerados una oportunidad para reflejar hacia el exterior la estabilidad económica y el liderazgo de Brasil. Este panorama sirvió como factor de atracción para inmigrantes limítrofes y de otros países.

Para 2010, se estimó que casi 600000 extranjeros residían en Brasil, lo que representaría alrededor del $0,3 \%$ de la población total. Esta cifra de inmigrantes fue muy similar a la de 2000 y la novedad consistió en que los estadounidenses se ubicaron como una de las principales colectividades de extranjeros, junto a las comunidades de portugueses, japoneses y de originarios de países limítrofes (OIM, 2018). 
Pero, de cara a la celebración del Mundial de Fútbol en 2014 y previo a los Juegos Olímpicos de 2016 - y en un contexto de crecimiento económico-, el número de extranjeros creció de forma exponencial. Un informe de la Policía Federal brasilera de 2015 reveló que en el país suramericano había 1847274 inmigrantes regulares, de los cuales 1189947 estaban de forma permanente, 595800 de manera temporal, 45404 en carácter provisorio, 11230 tenían la calidad de fronterizos, 4842 eran refugiados y 51 asilados (Dos Santos \& Assunção, 2016), aunque no se revelaron los orígenes de los migrantes, ${ }^{9}$ y tampoco se incluyeron datos sobre los extranjeros en condición irregular. ${ }^{10}$

Respecto al incremento de la inmigración en un período tan corto, el entonces secretario de Justicia, Paulo Abrão, señaló ante medios de comunicación ${ }^{11}$ que la consolidación de Brasil en el mercado internacional, la llegada de inversiones extranjeras y el desempleo en países centrales europeos eran los principales factores para la llegada de más extranjeros que buscaban insertarse en diferentes sectores económicos, incluido el de tecnología e información.

En concordancia con Abrão, la exdirectora del Departamento de Extranjeros del Ministerio de Justicia, Izaura Miranda, comentó que el aumento de extranjeros regulares en el país también obedecía a una amnistía migratoria aprobada en 2009 (Ley 11961), a la que se acogieron unas 45000 personas, y a la vigencia del Acuerdo sobre Residencia del Mercosur, que también entró en vigor en 2009 (Gobierno de Brasil, 2011).

\footnotetext{
9 En 2011, el Departamento de Justicia indicó que los grupos de inmigrantes regulares más copiosos en Brasil eran los portugueses (328856), bolivianos (50640), argentinos (42163), chinos (35265) y paraguayos (17 604) (Gobierno de Brasil, 2011).

10 Organizaciones no gubernamentales y religiosas, como Conectas Derechos Humanos y la Confederación Nacional de los Obispos de Brasil (CNOB), estimaron en 600000 el número de inmigrantes sin documentos en Brasil al finalizar la primera década del siglo XXI (cfr. Conectas, 2016); sin embargo, no hay certeza sobre el dato en la actualidad, pues se debe considerar que tras la conclusión de los Juegos Olímpicos de Río de Janeiro 2016 se incrementó la salida de extranjeros, particularmente de haitianos, de territorio brasilero en búsqueda de oportunidades laborales en el norte del continente.

11 En entrevistas con medios de comunicación en 2011, el secretario destacaba la pujanza económica brasilera y la atracción de nuevos inmigrantes. Cfr. http://www.lanacion.com. ar/1422801-brasil-la-nueva-tierra-prometida-de-los-inmigrantes
} 
De esta forma, Brasil se consolidó como un polo de atracción de migrantes limítrofes, pero también de poblaciones provenientes de países africanos, ${ }^{12}$ de Haití — de donde salieron miles de personas tras una serie de desastres naturales y encontraron empleos en territorio brasilero-y de otros Estados fuera de la región suramericana, lo que llevó a funcionarios brasileros, incluido el secretario Abrão, a pedir la aprobación de una nueva ley migratoria para flexibilizar el ingreso de extranjeros.

\section{La emigración brasilera en la actualidad}

Las cifras manejadas por autoridades, especialistas y agencias internacionales sobre los nacionales de Brasil en el extranjero difieren; por ejemplo, el Ministerio de Relaciones Exteriores estimó en 3,7 millones el número de brasileros en el exterior en 2010, mientras la OIM consideró que habría entre 1 y 3 millones (IBGE, 2011, p. 55).

Tabla 1. Principales países de destino de los emigrantes brasileros hasta 2008

\begin{tabular}{|l|c|}
\hline \multicolumn{1}{|c|}{ País } & Número de brasileros residentes \\
\hline Estados Unidos & 1240000 \\
\hline Paraguay & 487517 \\
\hline Japón & 310000 \\
\hline Reino Unido & 150000 \\
\hline Portugal & 147500 \\
\hline Italia & 132000 \\
\hline España & 110000 \\
\hline Suiza & 55000 \\
\hline Alemania & 46209 \\
\hline Bélgica & 43638 \\
\hline Argentina & 38500 \\
\hline Francia & 30000 \\
\hline Canadá & 20650 \\
\hline Guayana Francesa & 20000 \\
\hline
\end{tabular}

12 En 1997 se aprobó en Brasil una nueva ley sobre refugio, a la que se acogen una parte importante de los africanos que llegan al país suramericano. De acuerdo con datos del Ministerio de Justicia de Brasil (2016), entre los principales beneficiados con la figura de refugiado se encuentran angoleños, congoleses, liberianos y sierraleoneses. 


\begin{tabular}{|l|c|}
\hline \multicolumn{1}{|c|}{ País } & Número de brasileros residentes \\
\hline Uruguay & 18848 \\
\hline México & 18000 \\
\hline Irlanda & 17000 \\
\hline Holanda & 16000 \\
\hline Bolivia & 15091 \\
\hline Israel & 15000 \\
\hline
\end{tabular}

Fuente: elaboración del autor con base en datos del Ministerio de Relaciones Exteriores de Brasil y publicado por la OIM (2010, p. 39).

La discrepancia sobre cuál es la cifra más cercana a la realidad continúa, empero las diferentes versiones comparten los principales lugares de destino en los que habitan los brasileros. La lista la encabeza Estados Unidos, seguido por Portugal, España, Japón, Italia e Inglaterra, que concentrarían el 70\% de los brasileros en el exterior (IBGE, 2011, p. 57). Este conjunto de países desarrollados requerían de mano de obra en la década de 1990 y a mediados de la primera década del nuevo siglo, cuando registraban altas tasas de crecimiento. Además, salvo los dos Estados anglosajones, el resto promovió políticas para que descendientes de sus connacionales que hicieron vida en América Latina como migrantes pudieran acceder a la ciudadanía otorgada por los citados países europeos.

Mención especial merecen una parte importante de los brasileros en Paraguay, pues aún no se reconoce de forma oficial a buena parte de los denominados 'brasiguayos' como ciudadanos de Brasil luego de los problemas generados por los asentamientos de brasileros en las áreas rurales paraguayas de los mencionados departamentos de Alto Paraná, Canindeyú y Amambay, fronterizos con Brasil, tras el malogrado acuerdo bilateral de 1975. Los que sí son reconocidos como brasileros suelen ser terratenientes en las zonas fronterizas con el Estado paraguayo y las mujeres se concentran en el servicio doméstico y el comercio (OCDE, 2010, p. 239).

También destacan las migraciones de brasileros hacia países latinoamericanos, sobre todo a los limítrofes, como Argentina, Uruguay y Bolivia, que forman parte del proyecto de integración económica y 
política del Mercosur, y en donde los brasileros se han insertado en los últimos años en actividades laborales de servicios, comercio e industria (Texidó, et al., 2003, pp. 44-75).

\section{El retorno de connacionales a Brasil}

El último patrón de gran envergadura que afronta en la actualidad Brasil es de carácter emergente y tiene que ver con el retorno de connacionales provenientes de países desarrollados en los que la crisis financiera y económica mundial de 2008 cerró o disminuyó oportunidades laborales, por lo que emprendieron el camino de regreso a un Brasil que proyectaba estabilidad y grandes esperanzas.

A partir de 2008, se registró un incremento en el número de retornos de suramericanos a sus países de origen provenientes de países desarrollados, en un marco caracterizado por la crisis financiera global, pero también por la aprobación o endurecimiento de normas migratorias en Estados Unidos y la Unión Europea, de forma particular. ${ }^{13}$

En España, uno de los destinos más relevantes para los emigrantes latinoamericanos, se observó una salida de 24000 suramericanos en 2010 y de más de 41000 en 2011, la mayoría de ellos originarios de Argentina, Bolivia, Brasil y Ecuador (Texidó \& Gurrieri, 2012, p. 44). En el caso particular de los brasileros, las autoridades españolas registraron un retorno de 4701 personas hacia territorio brasilero en 2010 y de 7708 un año después, situación que se apreció también en otros destinos, como Italia, Portugal, Estados Unidos y Japón. Sobre este último país asiático, en el año 2009 salieron unos 50000 brasileros con destino a sus comunidades de origen (OIM, 2010, p. 12).

Debido a una serie de dificultades técnicas y de criterios, así como a la magnitud de las migraciones internacionales, resulta complicado

\footnotetext{
13 En Estados Unidos desde 2001 se empezaron a aplicar una serie de medidas para restringir aún más la inmigración, especialmente la irregular. En el caso de la Unión Europea, el caso más emblemático de endurecimiento fue la adopción en 2008 de la Directiva de Retorno, que permite hacer a sus Estados miembros detenciones de indocumentados más prolongadas y expulsiones más expeditas.
} 
obtener cifras precisas, empero en el último censo de población, el de 2010, se detectaron poco más de 290000 brasileros retornados ${ }^{14}$ del extranjero, en su mayoría procedentes de Estados Unidos y de Japón, situación que obligó a implementar una serie de medidas para atender a este sector poblacional.

\section{La apertura política de Brasil, sociedad civil y compromisos internacionales}

Además del paulatino reconocimiento de los patrones migratorios afrontados por Brasil, el cambio de paradigma en la política migratoria es también resultado de elementos políticos internos, de las exigencias de la sociedad civil, así como de una serie de compromisos internacionales asumidos por el Estado suramericano en la materia.

Es necesario recordar que la política migratoria de puertas cerradas fraguada durante la última dictadura militar identificaba al extranjero como un peligro para la actividad económica y la seguridad nacional. La base de esa visión fue la Ley 6815 o Estatuto del Extranjero, aprobada en la presidencia de João Baptista de Oliveira Figueiredo (19791985) y en la que se restringió el otorgamiento de visas, de entradas y de salidas, se aceleraron los procedimientos para las deportaciones, expulsiones y extradiciones, y se penalizaba a los inmigrantes indocumentados o a los regulares que hubieran cometido faltas de carácter político, económico, social o moral (Senado Federal, 2013, pp. 18-19).

Los militares estaban "particularmente descontentos" con la interferencia de religiosos extranjeros en asuntos considerados como internos, por lo que buscaron mecanismos para facilitar la expulsión de Brasil de los inmigrantes involucrados en actividades políticas (Reis, 2011, p. 59). Además, la junta justificó la política migratoria y la expedición

\footnotetext{
14 En algunas organizaciones y trabajos académicos se considera que el número de retornados hasta 2015 habría pasado el millón de personas, aunque no hay cifras oficiales. El censo de 2010 indica que de Estados Unidos regresaron 64138 brasileros; de Japón, 53 825; de Portugal, 26609; de Paraguay, 26274; del Reino Unido, 18391; de España, 17884; de Italia, 14254; y de otros países, 77884 (Cavalcanti, 2015, p. 151).
} 
de la ley como mecanismos de relevancia para procurar la seguridad nacional, la institucionalidad, los intereses políticos, sociales, económicos y culturales, así como la defensa de los intereses de los trabajadores locales (Dos Santos \& Assunção, 2016) ante la competencia que supondrían los extranjeros. ${ }^{15}$

Esta ley, que con una serie de enmiendas siguió vigente hasta la entrada en vigor de la nueva normativa a finales de 2017, no contemplaba otros factores de relevancia en la cambiante realidad migratoria brasilera, entre ellos la vinculación y atención de la creciente presencia de brasileros en el extranjero.

El regreso de los gobiernos civiles a Brasil a partir de 1985 trajo consigo el paulatino abandono de la Doctrina de la Seguridad Nacional impuesta por los militares al momento de elaborar políticas públicas y una apertura hacia la cooperación internacional en temas relacionados con la salvaguarda de los derechos humanos y el libre comercio. Al mismo tiempo, el mito de que el país era solo receptor de migrantes empezó a desvanecerse ante el incremento del número de brasileros en el extranjero en búsqueda de un futuro más próspero, situación que fue retratada por periódicos y televisoras como "un síntoma de fracaso del país para atender las grandes expectativas referentes al desarrollo económico y social" (Reis, 2011, p. 47) del Estado.

Con el reconocimiento de las colectividades brasileras en el extranjero, se inició la creación de programas y la implementación de acciones para atender a sus connacionales en el exterior, y de manera posterior a los refugiados y a los inmigrantes intrarregionales, luego de la firma y ratificación de tratados, convenciones y acuerdos internacionales, ${ }^{16}$ que obligaban al Estado brasilero a tener una normatividad alejada de la visión militar y comprometida con el respeto a los derechos humanos.

\footnotetext{
15 Una de las paradojas de la ley de 1980 es que en su artículo $2^{\circ}$ promovía la atracción de mano de obra calificada, pero en la práctica se restringía.

16 Aunque el Estado brasilero no forma parte de la Convención Internacional sobre la Protección de todos los Trabajadores Migratorios y sus Familias, de 1990, sí ha firmado y ratificado otros instrumentos relacionados con la protección a los derechos humanos de los migrantes, entre ellos la Convención sobre los Derechos del Niño (1989), la Convención
} 
En 2004, por ejemplo, Brasil fue impulsor de la creación del Foro Social Mundial de las Migraciones, en el marco del Foro Social Mundial, por medio del cual se comprometió a promover y garantizar el respeto a los derechos de los migrantes junto a otros Estados, organizaciones internacionales gubernamentales y no gubernamentales, así como otros actores. En el mismo año, el Estado suramericano ratificó la Convención de las Naciones Unidas contra la Delincuencia Organizada Transnacional y sus protocolos, relacionados con la movilidad humana, el primero destinado a prevenir, reprimir y sancionar la trata de personas, especialmente de mujeres y niñas; y el segundo contra el tráfico ilícito de migrantes por tierra, mar y aire.

Pero, a pesar de los compromisos internacionales, Brasil carecía de una nueva ley de migración y fracasaron algunos intentos por contar con una nueva, por ejemplo, en el período en el que estuvo al frente del país el expresidente Fernando Henrique Cardoso (1995-2002) se envió una iniciativa de nueva ley de extranjeros al Congreso Nacional, pero, tras ser sujeta a decenas de enmiendas y de permanecer congelada por años, la propuesta terminó por ser retirada.

Años después, durante el primer mandato de Luiz Inácio Lula da Silva se llevó a cabo en 2005 una consulta pública para analizar proyectos de nueva legislación, empero es hasta 2009 cuando se retoma el tema en el Congreso (Sprandel, 2015, p. 47), pero otra vez la carencia de consenso impidió contar con una nueva normativa por varios años más; a pesar de lo anterior, otro elemento que permitió tener respuestas estatales más abiertas hacia los procesos de migración internacional fue la participación de Brasil en el Mercosur.

\section{Brasil y el área de libre residencia en el Mercosur}

Al iniciar la década de 1990, en un contexto de mayor liberalización de los mercados y con la tendencia internacional de incentivar la creación de nuevos bloques regionales, entre ellos el Mercosur, para competir 
en el comercio internacional de bienes y servicios, el Estado brasilero asimiló que había dejado de ser un país estrictamente destinatario de inmigrantes, provenientes sobre todo de Europa y Japón, para ser un país expulsor de connacionales y receptor de corrientes originadas en su mayoría de países limítrofes.

El Mercosur nació en 1991 como un proyecto de libre comercio y de desarrollo económico con la participación de Brasil, Argentina, Uruguay y Paraguay, ${ }^{17}$ pero, con el transcurso de los años y la incorporación de nuevos tratados e integrantes asociados, el bloque evolucionó hasta considerar a la migración internacional como parte esencial de un proceso de integración económico, político y social.

Después de varios tratamientos y discusiones a lo largo de más de una década, se aprobó el Acuerdo sobre Residencia para los Nacionales de los Estados Partes del Mercosur, Bolivia y Chile en diciembre de 2002, cuyos principales objetivos son fortalecer la integración regional, regularizar la inmigración indocumentada, combatir el tráfico de personas, dar cauce a la movilidad laboral, proteger los derechos fundamentales de los migrantes y facilitar el otorgamiento de residencias temporales y permanentes a personas originarias de los países del Mercado Común del Sur ampliado. ${ }^{18}$

Para la entrada en vigor del acuerdo migratorio se necesitaba la ratificación de los seis países firmantes y el aviso de internacionalización de lo estipulado en el documento, pero, producto de las asimetrías políticas, económicas, institucionales y legales entre los firmantes, el instrumento inició su vigencia formal en todo el bloque ampliado hasta 2009.

\footnotetext{
17 El instrumento constitutivo del Mercosur es el Tratado de Asunción, firmado el 26 de marzo de 1991. Cuatro años después se firmó el Protocolo de Ouro Preto, por medio del cual se estableció un arancel externo común.

18 El Mercosur ampliado se refiere a los Estados partes y a los asociados. Los países fundadores y partes son Argentina, Brasil, Uruguay y Paraguay. Venezuela se adhirió de forma plena en 2013, aunque sus derechos se suspendieron en 2016 por incumplir la internalización de los instrumentos normativos del bloque. Los Estados en condición de asociados y que también entran en la órbita del Acuerdo sobre Residencia son Bolivia y Chile, a los que se han sumado Colombia, Ecuador y Perú.
} 
Brasil y Argentina fueron los principales promotores del acuerdo y desde 2005 el Estado brasilero declaró estar en posibilidad de cumplir con el instrumento y registró una serie de avances bilaterales en su aplicación por medio de decretos presidenciales avalados por el Congreso, sin necesidad de reformar o de cambiar la antigua ley de extranjeros de 1980 (Muñoz, 2011, pp. 59-65).

La disposición del Estado brasilero para apoyar un acuerdo migratorio intrarregional, que intenta garantizar a los inmigrantes del bloque los mismos derechos sociales, económicos, de movilidad y de salud que a los locales, obedeció en parte a los patrones de inmigración y emigración que presenta Brasil en la región suramericana, pero también se debió a la apuesta por renovar el proyecto de integración mercosureño en el que Brasil es líder y en donde proyecta su mayor influencia.

El Acuerdo sobre Residencia, así como otros instrumentos firmados de manera previa por Brasil de forma bilateral o multilateral, han sido fundamentales para que la política migratoria brasilera haya tenido una mayor apertura frente a las migraciones limítrofes, incluso sin derogar la ley de 1980, gracias a la implementación de órdenes ejecutivas, programas, amnistías y acciones concretas.

\section{La aprobación de la nueva ley de migración}

\section{y la participación ciudadana}

Durante 37 años, el Estatuto del Extranjero fue la piedra angular normativa sobre la que Brasil tuvo que trabajar para regular las migraciones dentro de su territorio. La falta de consensos en el Congreso impidió en varias ocasiones que se sancionara una nueva ley migratoria y solo fue posible en 1997 aprobar una iniciativa sobre refugiados, lo que obligó a los diferentes gobiernos a emitir órdenes ejecutivas para atender compromisos internacionales y poner en marcha programas y amnistías.

Finalmente, en 2017 se sancionó la nueva ley de migración, que es una consecuencia de la apertura de la política migratoria emprendida hace décadas por parte del Estado brasilero y es también en parte 
resultado de la labor emprendida por grupos de la sociedad civil comprometidos con el respeto de los derechos humanos de los migrantes.

Desde inicios del presente siglo, diferentes colectivos sociales y de migrantes se organizaron para presionar a los políticos y llevar al Congreso iniciativas de ley encaminadas a sustituir el Estatuto del Extranjero con el objetivo de proteger de mejor manera los derechos de los inmigrantes y de los propios brasileros radicados en el exterior.

Las demandas de movimientos sociales pro migrantes no solo se dieron a nivel federal, pues en ciudades como San Pablo se creó en 2013 la Secretaría de Derechos Humanos y Ciudadanía como respuesta a demandas de colectivos de inmigrantes para atender de forma transversal, junto a las demás secretarías, a migrantes y refugiados. "Esa primera coordinación de políticas para migrantes a nivel local en Brasil comenzó como una política de gestión y, debido a la demanda de la sociedad civil, fue transformada en 2016 en política de gobierno a través de ley municipal” (Feldman-Bianco, 2017).

También en 2013 representantes de colectividades de extranjeros, académicos, organizaciones de la sociedad civil e iglesias fueron convocados por autoridades federales para la realización de algunos foros, cuyos objetivos se centraron en atender los patrones de movilidad en Brasil con pleno respeto a los derechos humanos de los migrantes (Lussi, 2015, p. 55); sin embargo, tuvieron que pasar cuatro años más para que las resoluciones emitidas, al menos buena parte de ellas, tuvieran eco en una nueva normativa.

En abril de 2017 el Senado brasilero aprobó por unanimidad la iniciativa impulsada desde 2014 por el entonces legislador del conservador Partido de la Social Democracia Brasilera (PSDB), Aloysio Nunes Ferreira, y para mayo del mismo año se convirtió en ley tras la sanción del presidente Temer. Durante la discusión parlamentaria, agrupaciones como Misión y Paz y Conectas Derechos Humanos fueron convocadas para dar sus puntos de vista, además organizaciones e instituciones como el Frente de Mujeres Inmigrantes, Casa de las Áfricas, Salud sin Fronteras, Centro de Apoyo Pastoral del Migrante, 
el Servicio Franciscano de Solidaridad y el Centro de Referencia y Atención para Migrantes convocaron a marchas para apoyar la aprobación de una nueva normativa (Pina, 2016).

El proyecto de Ferreira contemplaba para los migrantes derechos sociales y económicos, libertades civiles, acceso a servicios públicos de salud, asistencia social, educación y justicia, así como el derecho a ejercer cargos o funciones públicas, y una amnistía a los inmigrantes irregulares establecidos en Brasil antes de julio de 2016, empero la ley sancionada por Temer vetó los dos últimos elementos y permite la expulsión de inmigrantes con menos de cuatro años de residencia en territorio brasilero que hubiesen cometido delitos.

La iniciativa de Ferreira fue elaborada en un momento en que Brasil aún vivía un auge económico y una estabilidad política relativa, solo cuestionada por una serie de protestas encabezadas por clases medias en contra de la realización del Mundial de Fútbol y de los Juegos Olímpicos debido a que consideraban onerosas las erogaciones y demandaban mejoras en los servicios sociales.

A diferencia de otros proyectos presentados años atrás, la iniciativa del entonces senador Nunes Ferreira contó con respaldos en el Congreso y en julio de 2015 se aprobó en comisiones del Senado, pero la inestabilidad política que llevó a la destitución de Dilma Rousseff en 2016 y el controvertido ascenso de Temer al poder retrasaron la aprobación en el pleno y su respectiva promulgación como nueva ley. Finalmente, la discusión se retomó y el 24 de mayo de 2017 se sancionó la nueva normativa.

A pesar de los vetos que impuso Temer, que son resultado en parte de la presión de grupos de derecha alineados con la visión de restricción y de seguridad ante la inmigración, la nueva ley cumple con la normatividad internacional en materia de derechos humanos, laborales, sociales, educativos y de salud, aunque enfrentará una serie de retos para su implementación y deja un hueco respecto a los inmigrantes indocumentados que viven en la actualidad en Brasil. 
Entre las situaciones más apremiantes para la cumplimentación de la nueva ley destaca la coordinación interinstitucional que deberá tener una serie de agencias del Estado brasilero que en el pasado han presentado duplicidades al momento de actuar o poca o nula cooperación. El Consejo Nacional de Inmigración (CNIg), que es un órgano colectivo integrado por representantes de cuatro sectores: gobierno, trabajadores, empleadores y sociedad civil, y está presidido por el Ministerio del Trabajo y Empleo, debe trabajar para que entidades como la Policía Federal, los ministerios de Relaciones Exteriores, de Justicia, de Trabajo, de Salud y de Educación cooperen con el fin de atender los diferentes patrones migratorios internacionales que vive Brasil, a través de una visión de respeto a los derechos humanos y no de seguridad.

La nueva ley, vigente desde el 21 de noviembre de 2017, contempla las figuras de migrante, inmigrante, emigrante, apátrida y refugiado, a los que se les garantiza normativamente el respeto a sus garantías individuales, a sus derechos laborales y sociales, sin distinción de su calidad de regularidad o irregularidad; sin embargo, Brasil es un país complejamente burocrático —y los procedimientos migratorios requieren de simplificación- (Povóa \& Sprandel, 2010, p. 62). Así mismo, el Estado aún resiente las secuelas de la reciente crisis económica, cuenta con recursos limitados para atender los retos que suponen los diferentes patrones migratorios y requiere conformar una institución con plena autonomía para aplicar la nueva legislación, ya que el Consejo Nacional de Inmigración aún carece de las herramientas legales, presupuestales y de personal para conducir los trabajos interinstitucionales.

\section{Otras respuestas del Estado brasilero ante la migración internacional}

En las últimas dos décadas, las labores en materia migratoria han girado en torno a los tres patrones migratorios de mayor relevancia que vive Brasil. En el caso de la inmigración, Brasil ha puesto en marcha tres amnistías, las de 1988, 1998 y 2009, para regularizar la situación de miles de inmigrantes sin documentos. La última de estas dispensas contempló opciones para que los inmigrantes regularizados 
tuvieran acceso al mercado de trabajo en las mismas condiciones de igualdad que los nacionales en materia laboral, salud pública, educación gratuita, acceso al sistema bancario y de crédito, y el derecho de ir y venir dentro del territorio (Póvoa \& Sprandel, 2010, p. 67).

$\mathrm{Al}$ reconocer que Brasil se convirtió en un importante receptor de inmigración limítrofe, las autoridades también emprendieron una serie de convenios bilaterales en la década de 2000 con Bolivia, Paraguay, Uruguay y Argentina, para regularizar la situación de los inmigrantes o para mejorar sus condiciones de vida en la nación receptora (Muñoz, 2011, p. 58).

Para atender el patrón de la inmigración, en su vertiente de asilo, también se han gestado una serie de acciones, como la aprobación de la Ley 9474 de 1997 y la creación del Comité Nacional para los Refugiados (Conare) en 1998, destinados a la atención de los solicitantes de refugio, provenientes principalmente del continente africano, pero también de Colombia, de Haití y, más recientemente, de Venezuela, y a su integración en la vida social y económica en Brasil. Incluso el Estado brasilero recurrió a una serie de decisiones ejecutivas y resoluciones para relajar la normativa de 1980 y así conceder visas y permisos de permanencia a extranjeros víctimas de trata de personas (como la Resolución 93/2010), tema en el que Brasil también ha puesto interés.

En la nueva normativa sancionada en 2017 también se incluyeron elementos para facilitar la llegada de migrantes económicos altamente calificados, inversores y personas que realicen actividades con "relevancia económica, social, científica, tecnológica y cultural" (Presidencia de la República de Brasil, 2017).

En lo referente al patrón de la emigración, el Ministerio de Relaciones Exteriores brasilero ha ampliado sus obligaciones y, además de recibir y aprobar las solicitudes de entrada a Brasil por parte de extranjeros, también se ha convertido en un instrumento de recolección de información, de vinculación, de protección y de atención de los brasileros en el exterior a través de su red consular. 
Desde mediados de la década de 1990 se ha venido construyendo un andamiaje en la cancillería brasilera, constituido por la Subsecretaría General para las Comunidades Brasileras en el Exterior (SGEB, por su sigla en portugués), el Departamento Consular de Brasileros en el Exterior, la División de Asistencia Consular, la División de las Comunidades Brasileras en el Exterior y la División de Documentos de Viaje, en una apuesta por parte del gobierno federal para mantenerse en contacto con sus connacionales en el exterior, que hasta 2012 superaban los 3 millones, según datos del propio Ministerio de Relaciones Exteriores.

La capacidad organizativa de agrupaciones de brasileros en el extranjero, el creciente número de emigrados y, en menor parte, la relevancia de las remesas enviadas a Brasil —que en 2015 se ubicaron en 2809 millones de dólares (Fundación BBVA \& Conapo, 2015, p. 192)— ${ }^{19}$ han sido elementos fundamentales para entender el reconocimiento de las comunidades brasileras en el extranjero por parte del Estado, y una prueba de ello es la promulgación en 2007 de una enmienda constitucional para restituir la nacionalidad a los hijos de brasileros nacidos en el exterior (OIM, 2010, p. 66), así como la inclusión de un apartado (el capítulo VII) en la nueva ley de migración dedicado a las acciones de protección y vinculación con los brasileros en el exterior.

Concatenado con el patrón de la emigración, está el de retorno, situación que se hizo más visible a partir de la crisis financiera y económica de 2008, y que afectó particularmente algunos de los puntos principales de destino de los brasileros en el exterior, como son Estados Unidos, Japón, España, Portugal e Italia. En este sentido, el Estado brasilero ha tenido que implementar programas y acciones por medio de varios de sus ministerios, incluidos el de Relaciones Exteriores y el de Trabajo y Empleo, para hacer frente a esta emergencia.

\footnotetext{
19 En cuanto al monto, Brasil se ubica en el séptimo lugar entre los principales países receptores de remesas en América Latina y el Caribe, después de México (25 689 millones de dólares), Guatemala (6408), República Dominicana (4986), Colombia (4514), El Salvador (4357) y Honduras (3931); sin embargo, porcentualmente hablando, las remesas no resultan tan significativas en su PIB como sí lo son para El Salvador, Guatemala, Honduras o Perú.
} 
El Ministerio de Relaciones Exteriores calculó en 600000 el número de brasileros que retornaron a sus lugares de origen en una década (Dos Santos, 2015, p. 76), y aunque cifras extraoficiales hablan del regreso de un millón de brasileros, es la coyuntura económica internacional la que llevó a la Cancillería a lanzar en septiembre de 2010 la Guía de retorno a Brasil, por medio de la cual se busca dar información precisa sobre programas, normas y acciones a las que pueden acceder para garantizar el respeto a sus derechos humanos.

La Guía, en cuya elaboración participaron el Ministerio de Justicia, el Departamento de Policía Federal y la Secretaría de Políticas para las Mujeres, sirve como eje para atender a los retornados y a los que están por retornar gracias a la intervención de la red consular. Para facilitar la revisión de las directrices, se abrió desde 2013 el Portal de Retorno, con el que se busca facilitar la reinserción social y económica de los brasileros por medio de la difusión de programas de obtención de documentación, de empleo, de apoyo para apertura de pequeños negocios, de capacitación, de educación financiera, de educación y salud, entre otros. ${ }^{20}$

\section{Consideraciones finales}

El Estado brasilero ha transitado de una política migratoria restrictiva, impuesta por la última dictadura militar, hacia una abierta y garantista de los derechos humanos, para responder a los principales patrones migratorios que afronta el país (inmigración, emigración y retorno), y en su formulación también influyeron elementos económicos y políticos, tanto internos como externos, afrontados por el país suramericano.

En el plano económico, y luego de que se definiera a la migración regional como factor de desarrollo en el Mercosur, las autoridades brasileras promovieron la facilitación del ingreso de extranjeros calificados y no calificados ante las favorables perspectivas de crecimiento que se tuvieron entre 2003 y 2014.

20 El portal se puede consultar en la dirección http://retorno.itamaraty.gov.br/pt-br/ 
Entre los factores políticos destacan el regreso a la democracia - y el abandono paulatino de la Doctrina de Seguridad Nacional_- la incorporación del Estado a tratados internacionales de protección a los derechos humanos, así como la pertenencia al Mercosur, mecanismo de integración desde el que Brasil y sus socios han trabajado por incorporar a la movilidad humana como factor de desarrollo del bloque.

Además, el activismo de grupos de la sociedad civil y de las propias colectividades de migrantes fue relevante para ejercer presión y aprobar una nueva ley de migración en 2017, que sustituyó al rígido Estatuto del Extranjero de 1980.

Esta política migratoria abierta cuenta ahora con una ley que cumple con los compromisos internacionales y regionales signados por el Estado, sin embargo, aún existe una serie de problemáticas que se deben atender para que la normativa y los programas cumplan con sus objetivos.

Entre los retos que tiene el Estado brasilero a corto plazo están el dotar de mayor autonomía al Consejo Nacional de Inmigración para coordinar a las diferentes dependencias relacionadas con el tema y capacitar al personal dedicado a atender a los migrantes; y está pendiente la firma y ratificación de la Convención Internacional sobre la Protección de los Trabajadores Migratorios y sus Familias.

Otros elementos por atender son la negativa a otorgar una amnistía a los inmigrantes irregulares que ingresaron a Brasil antes del 6 de julio de 2016 — cuya cifra podría ser de medio millón de personasy avanzar en la implementación del Acuerdo sobre Residencia, que obliga al Estado brasilero a garantizar los derechos laborales, sociales, de salud, de educación y jurídicos de los migrantes provenientes de los países integrantes del Mercosur en igualdad de condiciones que los nacionales brasileros, pero sin caer en discriminaciones hacia otras comunidades de extranjeros ajenos al bloque mercosureño.

En materia presupuestal, organizaciones no gubernamentales han advertido que el gobierno brasilero no ha dedicado los recursos y 
esfuerzos adecuados para cubrir las necesidades de solicitantes de asilo, por ejemplo, para tramitar sus peticiones. También han denunciado que algunos inmigrantes "han sufrido discriminación de manera habitual cuando intentaban acceder a servicios públicos tales como la atención a la salud y la educación” (Amnistía Internacional, 2017).

Finalmente, Brasil afronta dos situaciones de marcada relevancia, la primera es el arribo masivo de venezolanos, más de 52000 entre 2017 y 2018 (OEA, 2018), y que generó brotes xenofóbicos y ataques a campamentos de inmigrantes en municipios del fronterizo y norteño Estado de Roraima; y la segunda es el triunfo del candidato de ultraderecha Jair Bolsonaro en las últimas elecciones presidenciales.

Respecto a los venezolanos, el Estado brasilero tiene la obligación de aplicar tanto la normativa actual como los diferentes programas existentes para atender la situación, en conjunto con gobiernos del área y de organizaciones internacionales, y así evitar nuevos hechos de violencia y generar acciones tendientes a facilitar la estancia de los originarios de Venezuela, que podría ser prolongada.

Bolsonaro, por su parte, representa un riesgo para la actual política migratoria progresista formulada en las últimas décadas, pues, además de ser un exmilitar que añora la dictadura, podría poner en marcha algunas de las propuestas que lo llevaron a ganar la elección en octubre de 2018, entre ellas la de crear campos de concentración para venezolanos y la de cerrar las puertas del país a los inmigrantes.

\section{Referencias}

Amnistía Internacional. (2017). Informe 2016/2017 Amnistía Internacional. La situación de los derechos bumanos en el mundo. Recuperado de https:/ /www. amnesty.org/download/Documents/POL1048002017sPANISH.PDF

Banco Mundial. (2016). Country overview of Brazil. Recuperado de http:// www.worldbank.org/en/country/brazil/overview

Banco Mundial. (2017). Crecimiento del PIB anual. Recuperado de http://datos. bancomundial.org/indicador/NY.GDP.MKTP.KD.ZG 


\section{4 / Tomás Milton Muñoz Bravo}

Cavalcanti, L. (2015). Inmigrantes retornados de España. Un acercamiento a los programas de retorno de Brasil. En F. Lozano Ascencio \& J. Martínez Pizarro (Eds.), Retorno en los procesos migratorios de América Latina. Conceptos, debates y evidencias (pp. 143-162). Río de Janeiro: ALAP.

Celade. (2000). IMLA: investigación de la migración internacional en Latinoamérica, base de datos. Recuperado de http:/ /www.cepal.org/celade/migracion/ imila/seleccion.asp?parametro $=\mathrm{BR} 00|\mathrm{R}| \mathrm{BRASIL} \% 202000$

Conectas. (2016). Derechos humanos de los migrantes y refugiados en Brasil: incompatibilidad de la legislación migratoria vigente con los derechos bumanos y arbitrariedades en la repatriación e impedimento de entrada al país. Recuperado de http://www.conectas.org/arquivos/editor/files/RPU_2017DireitosdosMigranteseRefugiadosesp_doc.pdf

Corte Interamericana de Derechos Humanos. (2003). Opinión Consultiva OC-18/03. Condición jurídica y derechos de los migrantes indocumentados. Recuperado de http://www.acnur.org/fileadmin/Documentos/ BDL/2003/2351.pdf?view=1

Dos Santos, E. (2015). A questão migratória no mundo globalizado. Brasileiros no exterior, a emigração e o retorno. En E. J. Peixo do Prado \& R. Cohelo (Coords.), Migrações e trabalho (pp. 69-78). Brasilia: Ministerio Público del Trabajo de Brasil.

Dos Santos, L. \& Assunção, T. (2016). Política de migração brasileira: o que esperar de uma política respaldada no estatuto do estrangeiro de 1980? Recuperado de http://www.nepo.unicamp.br/publicacoes/ anais/arquivos/12_LF.pdf

Feldman-Bianco, B. (2017). La cuestión migratoria en Brasil: paradojas y avances. Recuperado de https://www.clacso.org/megafon/pdf/Megafon_14_4_Bela-Feldman-Bianco.pdf

Fernandes, D., et al. (2015). A migração de retorno para o Brasil: estudo de caso dos brasileiros retornados da Península Ibérica. En F. Lozano \& J. Martínez (Eds.), Retorno en los procesos migratorios de América Latina. Conceptos, debates y evidencias (pp. 109-142). Río de Janeiro: ALAP.

Ferreira, F. H., et al. (2013). La movilidad económica y el crecimiento de la clase media en América Latina. Washington: Banco Mundial.

Fundación BBVA \& Conapo. (2015). Anuario de migración y remesas México 2016. México: Fundación BBvA-Conapo.

García, R.. \& Gainza, P. (2014). Economía, migración y política migratoria en Sudamérica: avances y desafíos. Migración y Desarrollo, 23, 69-97. 
Gobierno de Brasil. (2011). Economia brasileira atrai estrangeiros e imigração aumenta 50\% em seis meses. Recuperado de http://www.brasil.gov.br/ economia-e-emprego/2011/11/economia-brasileira-atrai-estrangeiros-e-imigracao-aumenta-50-em-seis-meses

Gomes, C. P. (2003). La migración laboral en Brasil. En E. Texidó, et al., Migraciones laborales en Sudamérica: el Mercosur ampliado (pp. 77-96). Ginebra: OIT.

González Martínez, E. (2003). La inmigración esperada: la política migratoria brasileña desde João VI hasta Getulio Vargas. Madrid: Consejo Superior de Investigaciones Científicas.

IBGE. (2011). Censo demográfico 2010. Características da população e dos domicilios. Resultados do universo. Río de Janeiro: IBGE.

Leal, F. (2003). La Doctrina de Seguridad Nacional: materialización de la Guerra Fría en América del Sur. Revista de Estudios Sociales, 15, 74-87. https://doi.org/10.7440/res15.2003.05

Lussi, C. (2015). Formulação legal e políticas públicas no trato das migrações nacionais e internacionais. En E. J. Peixo do Prado \& R. Cohelo (Coords.), Migrações e trabalho (pp. 41-54). Brasilia: Ministerio Público del Trabajo de Brasil.

Mármora, L. (2002). Las políticas de migraciones internacionales. Buenos Aires: Paidós.

Marquetti, A., Maldonado Filho, E. \& Lautert, V. (2014). La tasa de ganancia en Brasil 1953-2003. Razón y Revolución, (27), 89-114.

Massey, D., Durand, J. \& Malone, N. (2009). Detrás de la trama. Políticas migratorias entre México y Estados Unidos, México: Miguel Ángel Porrúa.

Micolta, A. (2005). Teorías y conceptos asociados al estudio de las migraciones internacionales. Trabajo Social, 7, 59-76. https://doi.org/10.15446/ts

Ministerio de Justicia y Seguridad Pública de Brasil. (2016). Refúgio em números. Recuperado de http://www.justica.gov.br/news/brasil-tem-aumentode-12-no-numero-de-refugiados-em-2016/20062017_refugio-emnumeros-2010-2016.pdf

Mondol, L. (2010). Políticas públicas migratorias: consideraciones finales para su discusión. En C. Zurbriggen \& L. Mondol (Eds.), Estado actual y perspectivas de las políticas migratorias en el Cono Sur (pp. 17-24). Montevideo: Flacso. 


\section{6 / Tomás Milton Muñoz Bravo}

Morse, R. (1964). The heritage of Latin America. En L. Hartz (Ed.), The founding of new societies (pp. 123-177). Nueva York: Harcourt, Brace \& World.

Muñoz Bravo, T. M. (2011). Migración y bloques regionales: retos actuales en UE, TLCANy Mercosur. La relevancia de los movimientos migratorios en la integración regional. Saarbrüken, Alemania: Editorial Académica Española.

Muñoz Bravo, T. M. (2015). Evolución de las politicas migratorias en el Mercosur. De las estrategias individuales de poblamiento a la formulación de una política común intrarregional. México: Universidad Iberoamericana.

OCDE. (2010). Perspectivas económicas de América Latina 2010. París: OCDE.

OEA. (2018). Informe de la misión de la OE A a la frontera Brasil-Venezuela. Recuperado de https://www.oas.org/es/sadye/documentos/Informe_Mision_OEA_Brasil_Venezuela.pdf

OIM. (2010). Perfil migratorio de Brasil 2009. Ginebra: OIM.

OIM. (2018). La OIM en Brasil. Recuperado de https://robuenosaires.iom. int/brasil

OIM. \& IPPDH del Mercosur. (2016). Migración, derechos humanos y política migratoria. Buenos Aires: OIM.

Patarra, N. (2011). Políticas públicas y migración internacional en Brasil. En L. M. Chiarello (Coord.), Las politicas públicas sobre migraciones y la sociedad civil en América Latina. Los casos de México, Brasily Colombia (pp. 151-238). Nueva York: Scalabrini International Migration Network. Pellegrino, A. (2003). La migración internacional en América Latina y el Caribe. Tendencias y perfiles de los migrantes. Santiago de Chile: Celade-Cepal-BID.

Pina, R. (2016). Organizaciones sociales de Brasil piden que la nueva ley de migraciones sea votada. Recuperado de https://www.brasildefato. com.br/2016/11/24/organizaciones-sociales-de-brasil-piden-que-lanueva-ley-de-migraciones-sea-votada/

Póvoa, N. H. \& Sprandel, M. A. (2010). Brasil: estado actual de las políticas migratorias. En C. Zurbriggen \& L. Mondol (Coords.), Estado actual y perspectivas de las politicas migratorias en el Mercosur (pp. 55-74). Montevideo: Flacso Uruguay.

Presidencia de la República de Brasil. Ley de Migración 13445 (2017). Recuperado de https://www.planalto.gov.br/ccivil_03/_ato20152018/2017/lei/113445.htm 
Reis, R. (2011). A política do Brasil para as migrações internacionais. Contexto Internacional, 33(1), 47-69. https: / / doi.org/10.1590/S0102-8529 2011000100003

Senado Federal de Brasil. Estatuto do Estrangeiro, regulamentação e legislação correlata (2013).

Sprandel, M. A. (2015). Marcois legais e políticas migratórias no Brasil. En E. J. Peixo do Prado \& R. Cohelo (Coords.), Migrações e trabalho (pp. 41-54). Brasilia: Ministerio Público del Trabajo de Brasil.

Tapia, J. (1980). El terrorismo de Estado. La Doctrina de la Seguridad Nacional en el Cono Sur. México: Nueva Imagen.

Texidó, E. \& Gurrieri, J. (2012). Panorama migratorio de América del Sur 2012. Buenos Aires: OIM.

Texidó, E., et al. (2003). Migraciones laborales en Sudamérica: el Mercosur ampliado. Ginebra: OIT.

Toledo, M. (2011). La abolición en el Brasil: movimientos sociales y políticos en el sudeste cafetalero. En C. Aguirre (Ed.), La abolición de la esclavitud en Hispanoamérica y Brasil: nuevos aportes y debates (pp. 40-65). Madrid: Fundación Ignacio Larramendi. 